\title{
EFFECTIVENESS OF LOW LEVEL LASER THERAPY (LLLT) AND DEXAMETHASONE PHONOPHORESIS IN MINIMIZING POSTOPERATIVE SWELLING VERSUS TRISMUS FOLLOWING SURGICAL REMOVAL OF MANDIBULAR IMPACTED THIRD MOLAR: A CLINICAL COMPARATIVE STUDY
}

\author{
Amira Zaied*, Sayed A. Rashed ${ }^{* *}$, Mohammed MA. Khalaf*** and Marwa S Ibrahim****
}

\begin{abstract}
Background and review: The quality of life experienced by patients following third molar surgery is increasingly becoming a health concern; surgical removal of wisdom teeth under local anaesthesia is widely carried out in general dental practice. This procedure is usually associated with postoperative pain, swelling, and trismus as direct and immediate consequences of the surgical procedure. Many clinicians have, emphasized the necessity for better pain, swelling and trismus control in patients who undergo third molar surgery, American Academy of Craniomandibular disorders and the Minnesota Dental Association recommendations have been cited as the most commonly employed methods of physiotherapy treatment such as; short wave diathermy, ultrasound (US) and Low level laser therapy (LLLT). ${ }^{(1)}$
\end{abstract}

Objective: The aim of this study is to evaluate the effectiveness of Low Level Laser Therapy (LLLT) and Dexamethasone phonophoresis on the post-operative clinical outcomes (facial swelling \& trismus) following lower third molar surgical removal

Patients \& Methods: The study was performed on 30 patients ( 16 males \& 14 females) aged 25-45 suffering from impacted mandibular third molar. They were divided into two equal groups; Group (A) received low level laser therapy immediately after third molar surgical extraction for (The laser has been given as output power $15 \mathrm{~mW}$, pulsed $80 \%$ and dose $4.3 \mathrm{~J} / \mathrm{sq} . \mathrm{cm}$ for 6 minutes for 7 days after surgery), Group (B) received phonophoresis of dexamethasone ampoule (in each session with half of $8 \mathrm{mg}$ ampule and $35 \mathrm{~g}$ ultrasound gel immediately after third molar surgical extraction ( 7 minutes session over the masseter muscle area for 7 days). Maximum inter-incisal opening MIO and facial swelling measurements were evaluated on pre-operative, 2nd day and $7^{\text {th }}$ day postoperatively.

* Department of Oral and Maxillofacial surgery, Faculty of Dentistry, Fayoum University Egypt.

** Department of Oral and Maxillofacial Surgery, Faculty of Dentistry, Ahram Canadian University, Egypt.

*** Department of Physical Therapy for Surgery, Faculty of Physical Therapy, Cairo University, Egypt.

**** El Fayoum General Hospital, Physical Therapy department, Egypt. 
Results: Results showed that there is no significant difference between administration of dexamethasone phonophoresis and (LLLT) for the reduction of postoperative edema and trismus. Also this study demonstrates that both Low level Laser Therapy and Dexamethasone Phonophoresis were significantly effective in decreasing trismus following third molar surgery as manifested by the highly increased Maximum Inter-incisal Opening MIO, but only dexamethasone phonophoresis has a significant effect on reduction of edema as manifested by significant decreasing of measurements (FM) while there was no significant difference on edema at $7^{\text {th }}$ day post-operatively in laser group.

Conclusion: This study demonstrates that there is no significant difference between LLLT and dexamethasone phonophoresis for reduction of edema and trismus but only dexamethasone phonophoresis has a significant effect on decreasing edema on seventh postoperative day.

Keywords: Third molar, low level laser therapy, Dexamethasone phonophoresis.

\section{INTRODUCTION}

The adverse effects of the wisdom tooth surgery on the quality of life has been reported to show a three-fold increase in patients who experience pain, swelling and trismus alone or in combinations; compared to those who were asymptomatic. Many clinicians have, thus, emphasized the necessity for better pain, swelling and trismus control in patients who undergo third molar surgery ${ }^{(2)}$. The use of local or systemic corticosteroids and non-steroidal antiinflammatory drugs are often recommended after surgical extraction of impacted lower third molars to abolish postoperative pain, but some of them may manifest side effects such as gastrointestinal irritation, systemic bleeding tendency, and allergic reactions. These observations justify efforts to find a method of postoperative pain control that does not induce side effects. In that sense, the use of low power laser offers promising possibilities ${ }^{(3)}$ Lowlevel laser therapy (LLLT) is an internationally accepted title for bio-modulation, which we use to achieve ideal therapeutic effects. It is a painless, reproducible, non-invasive, and applied without need of anaesthesia.

Laser therapy works on the principle of inducing a biological response through energy transfer that induce anti-inflammatory effects, stimulation of wound healing, stimulation of immune system, as well promoting vasodilatation and increasing cellular metabolism which are considering highly advantageous characteristics of the application of this type of laser ${ }^{(4)}$. (LLLT) known as Low-level Light Therapy or Photobiomodulation (PBM) which is considering a low intensity light therapy where the effect is photochemical not thermal. The light triggers biochemical changes within cells and can be compared to the process of photosynthesis in plants, where the photons are absorbed by cellular photoreceptors and triggers chemical changes (5). The swelling reduction effect of LLLT may be related to its ability to accelerate the regeneration of lymph vessels and decrease vascular permeability. A large number of reports exist regarding the effect of LLLT on the tissue repair process, especially the inflammatory processes that affect muscle tissue ${ }^{(3)}$. Several studies have shown that use of laser application reduced inflammation; the following actions have been proven to produce key elements, which aid in the reduction of edema, such as Enhancement of ATP, Stimulation of vasodilatation, Reduction in interkeukin-1, Stabilization of the cellular membrane, Acceleration of leukocytic activity, Increase prostaglandin synthesis, enhanced lymphocyte response, increased angiogenesis as well Enhancement of superoxide dismutase (SOD) levels ${ }^{(6)}$.

On other hand Phonophoresis is a technique in which ultrasound is used to drive a topical application of selected medication into the tissues. The greatest advantage of phonophoresis is that medication can be delivered via a safe, painless, 
and non-invasive technique. It is thought that active transport occurs as a result of increased membrane permeability during sonation ${ }^{(7)}$. Phonophoresis can provide a safe and painless alternative to injections for treatment of common inflammatory conditions such as bursitis, sprains, strains, and tendinitis. Phonophoresis has been studied in vivo with several anti-inflammatory drugs, including hydrocortisone, benzydamine, dexamethasone, and salicylates, and with anaesthetics, such as lidocaine, with variable results. In vitro studies on the phonophoresis effect of ultrasound, author reported that ultrasound enabled a greater transport of whole molecules across synthetic or organic semipermeable membranes than was afforded by sham ultrasound ${ }^{(8)}$. Dexamethasone has been extensively used during past few years in oral surgery owing to its high potency and longer half-life. It has predominant glucocorticoid action. Dexamethasone blocks phospholipase-A2 thereby reducing levels of prostaglandins, leukotriene involved in the pathogenesis of pain, edema and subsequent trismus. ${ }^{(9)}$ It also reduced edema by decreasing permeability of capillary endothelium and therefore reduced the amount of fluid, protein, macrophages and other inflammatory cells entering areas of tissue injury. ${ }^{(10)}$

\section{MATERIALS AND METHODES}

Thirty patients of both sexes (16 males and 14 females) with ages ranging from 25 to 45 years, suffering from impacted mandibular third molar were selected from maxillofacial surgery unit Faculty of Dentistry, EL Fayoum University. An informed consent was obtained from all the patients. After obtaining approval from EL Fayoum University research and ethical committee, Patients were classified randomly into two equal groups each group had 15 patients. The surgery done by one operator (senior operator).the wisdom teeth operated are classified as (Mesioangular Winter's classification, Level B Depth, Class II Pell and Gregory's classification ramus relationship and
Pederson difficulty index score $=5$ )

- Group (A) (Laser group) received low-level laser therapy immediately after third molar extraction surgery for $(6 \mathrm{~min} / \mathrm{session}$ over the masseter muscle daily for 7 days. ${ }^{(4)}$

- Group (B) (Dexamethasone phonophoresis) who received phonophoresis of dexamethasone ampoule (in each session with half of $8 \mathrm{mg}$ ampule and $35 \mathrm{~g}$ ultrasound gel immediately after third molar extraction ( 7 minutes / session over the masseter muscle area for 7 days). ${ }^{(11)}$

The following clinical criteria were included in the study; Age between 25-45 years, impacted third molars in the mesio-angular position and with class B of average depth. All patients had the same surgical procedure with close operative duration, all operations were performed by the senior surgeon who used standardized technique on all patients, Swelling was assessed by a modification of a 3 line measurements (Figure 1) using 5 fixed points on surgical side of the face and finding the average. The fixed points used were A; the most posterior point at the midline on the tragus, $\mathrm{B}$; lateral canthus of the eye $\mathrm{C}$; the most lateral point on the corner of the mouth, D; soft tissue pogonion which is the most prominent point at the midline on the chin and E; most inferior point on the angle of the .(mandible. The 3 lines were $\mathrm{AC}, \mathrm{AD}$ and $\mathrm{BE}$. Where the corner of the eye and angle of mandible is (BE), the tragus and lip commissure is (AC), the tragus and pogonion is $(\mathrm{AD})\left({ }^{12,13)}\right.$ figure (1).

A baseline measurement was carried out just before the surgery and similar measurements were carried out on day 2 (48 hours) and day 7 postsurgery. The difference between the postoperative and pre-operative measurements was calculated. Three readings were taken for each patient and average was determined.

The Maximum inter-incisal opening MIO was evaluated by measuring with a Vernier caliper Gauge 


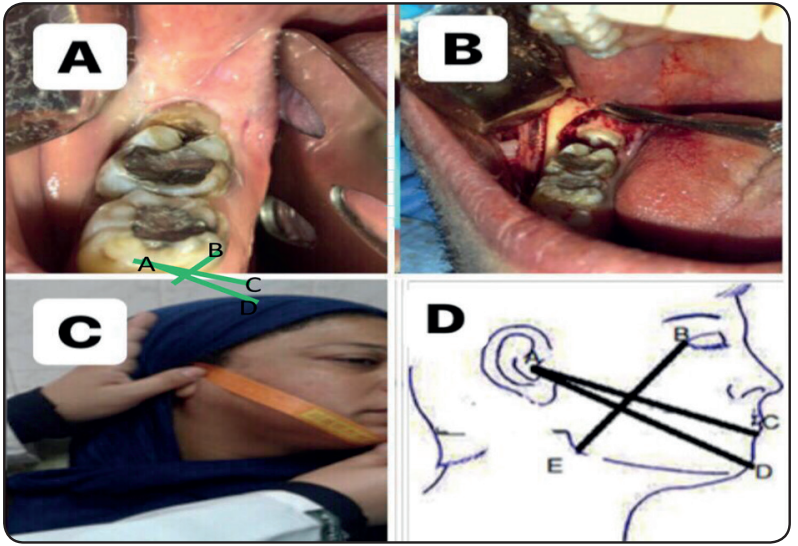

Fig. (1) : A. Preoperative photo of impacted lower wisdom B. guttering for surgical removal C \&D. Facial swelling measurements by joining 3 lines $\mathrm{AC}, \mathrm{AD}, \mathrm{BE}$.

the maximal opening between right maxillary and mandibular central incisors. Baseline measurements were taken just before the surgery and similar readings were carried out on days 2(48 hours) and 7 days postoperatively.

Laser device*, provides combined of visible (red) and infrared (invisible) laser irradiation. The device has the following treatment options: Wave length: from 640 to $950 \mathrm{~nm}$, Power output: $1 \mathrm{mw}$ up to $500 \mathrm{mw}$, Pulse duration: from $50 \mathrm{~ms}$ to $200 \mathrm{~ms}$., Frequency: from 1 to $10,000 \mathrm{HZ}$. Laser was applied on the surgical side for each patient immediately following third molar surgery. The patient will be instructed to wear the protective glasses. The laser was given as (infrared laser) wavelength $(950 \mathrm{~nm})$, output power $15 \mathrm{mw}$, pulsed $80 \%$ and dose $4.3 \mathrm{~J} /$ $\mathrm{cm} 2$ for 6 min.. The patients in this group received low-level laser therapy immediately after third molar extraction surgery for $(6 \mathrm{~min} /$ session over the masseter muscle daily for 7days) figure (2).

Ultrasound unit ${ }^{* *}$ has the following specifications: ax power consumption: $73 \mathrm{~W}$, Ultrasound fre-

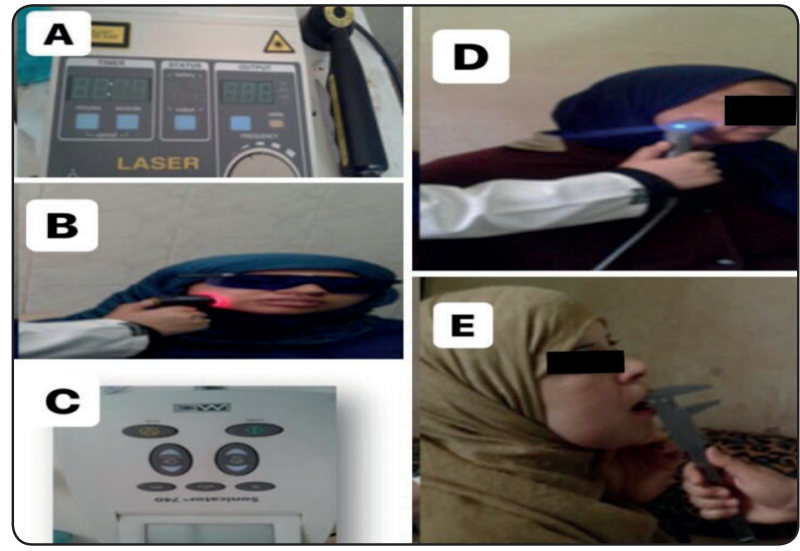

Fig. (2): A. Laser device B. Laser application on the surgical side C. Ultrasound unit D. ultrasound application over dexamethasone gel on the masseter muscle area $\mathrm{E}$. Interincisal opening was evaluated by measuring with a Vernier caliper Gauge.

quency: $1 \mathrm{MH} / 3 \mathrm{MH}$, Pulsed mode: output is continuous or pulsed, in pulsed mode: Output is $100 \%$ square wave modulated, Power level is adjusted with intensity control pulse amplitude. Dexamethasone ampule prepared for phonophoresis as following (in each session with half of $8 \mathrm{mg}$ ampule and $35 \mathrm{mg}$ ultrasound gel, ultrasound will be applied over dexamethasone gel $^{* * * *}$ on the masseter muscle area for 7 minutes, $1 \mathrm{MHz}$, pulsed $20 \%$ and dose 1,0 $\mathrm{W} / \mathrm{cm}^{2}$ figure (2).

\section{Statistical procedures and data analysis}

Data were collected and were transferred with statistical program SPSS version 21 to obtain the following statistical tools:

1. Descriptive statistic in the form of mean and SD.

2. Inferential statistics in the form of:

- Paired t-test to compare results of the same group.

\footnotetext{
* Electro Medical supplies manufactured by (Greenham)Ltd.Wantage,Oxfordshire,England

** (Sonicator 740), manufactured in UK).US has output of (AC 230 volt 50/60 Hz)

*** DECADRON® 7,5mg vial (preparation contains half of 1vial and 35 gm ultrasound gel)
} 
- Independent t-test to compare pre and post treatment test between the two groups.

- Repeated measures ANOVA to measure difference between 3 records in each group. Significance level is less than 0.05 .

\section{1- Characteristics of patients in both groups}

Thirty patients of both sexes (16 females and 14 males) with ages ranging from 25 to 45 years old, participated in the study. All patients were suffering from pain, swelling and trismus after lower third molar extraction surgery.

TABLE (1): Mean ages of patients in both groups

\begin{tabular}{|c|c|c|}
\hline & $\begin{array}{c}\text { Dexamethasone } \\
\text { phonophoresis }\end{array}$ & Laser \\
\hline Mean & 30.27 & 28 \\
\hline SD & 3.788 & 2.944 \\
\hline T value & \multicolumn{2}{|c|}{1.292} \\
\hline P value & \multicolumn{2}{|c|}{0.2071} \\
\hline Significance & \multicolumn{2}{|c|}{ Non- Ssignificant } \\
\hline
\end{tabular}

S.D: Standard deviation P: Probability value t: t test

\section{2- Laser group/ Maximum inter-incisal opening MIO in (mm):}

As shown in Table (2) paired t-test revealed that there was a significant difference in Maximum interincisal opening MIO preoperative (normal value) and $2^{\text {nd }}$ day postoperative which has an associated probability value less than 0.0001 . Also, there was a significant difference in Maximum inter-incisal opening MIO $2^{\text {nd }}$ day and $7^{\text {th }}$ day post-operative, which has an associated probability value less than 0.0001 . But, there was no significant difference in Maximum inter-incisal opening MIO in mm between preoperative and $7^{\text {th }}$ day postoperative which has an associated probability value 0.6472 (improved as it reached to its pre-operative normal value).

\section{2- Laser group/ facial measurements in ( $\mathrm{mm})$}

As shown in figure (3), paired t-test revealed that there was a significant difference in summation of facial measurement preoperative (normal value) and $2^{\text {nd }}$ day postoperative which has an associated probability value less than 0.0001 . Also, there was a significant difference in summation of facial measurement $2^{\text {nd }}$ day and $7^{\text {th }}$ day postoperatively which has an associated probability value less than 0.0001 . Moreover, there was a significant difference in summation of facial measurement between preoperative(normal value) and $7^{\text {th }}$ day postoperative which has an associated probability value 0.0006 (not improved as it couldn't reach to its preoperative normal value.

TABLE (2): Mean values of Laser group/ Maximum inter-incisal opening MIO in mm: (preoperative (pre) versus postoperative day 2 (D2) - postoperative day 2 (D2) versus postoperative day 7 (D7) and preoperative versus postoperative day 7

\begin{tabular}{|c|c|c|c|c|c|c|}
\hline & \multicolumn{2}{|l|}{ Pre } & \multicolumn{2}{|c|}{ D2 } & \multicolumn{2}{|c|}{ Pre $\quad$ D7 } \\
\hline Mean & $39.4 \mathrm{~mm}$ & $20.8 \mathrm{~mm}$ & $20.8 \mathrm{~mm}$ & $39.2 \mathrm{~mm}$ & $39.4 \mathrm{~mm}$ & $39.2 \mathrm{~mm}$ \\
\hline SD & 02.64 & 02.24 & 02.24 & 02.007 & 02.64 & 02.007 \\
\hline Mean difference & \multicolumn{2}{|c|}{$18.6 \mathrm{~mm}$} & \multicolumn{2}{|c|}{$-18.4 \mathrm{~mm}$} & \multicolumn{2}{|c|}{$00.2 \mathrm{~mm}$} \\
\hline $\mathrm{T}$ value & \multicolumn{2}{|c|}{30.211} & \multicolumn{2}{|c|}{29.886} & \multicolumn{2}{|c|}{0.4677} \\
\hline P value & \multicolumn{2}{|c|}{0.0001} & \multicolumn{2}{|c|}{0.0001} & \multicolumn{2}{|c|}{0.6472} \\
\hline Significance & \multicolumn{2}{|c|}{ Significant } & \multicolumn{2}{|c|}{ Significant } & \multicolumn{2}{|c|}{ Not significant } \\
\hline
\end{tabular}




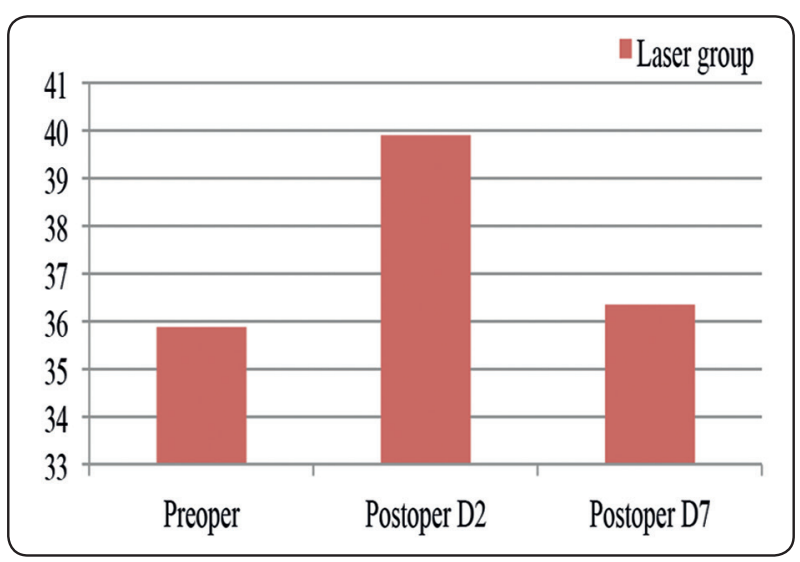

Fig. (3): Mean values in mm of facial measurements of laser group (preoperative-postoperative day 2- postoperative day 7)

\section{3- Dexamethasone phonophoresis group/ Maxi- mum inter-incisal opening MIO in mm}

As shown in Table (3) paired t-test revealed that there was a significant difference in pre-operative Maximum inter-incisal opening MIO (normal value) and 2nd day postoperative which has an associated probability value less than 0.0001 . Also, there was a significant difference in Maximum inter-incisal opening MIO 2nd day and 7th day postoperatively, where which has an associated probability value less than 0.0001. But, there was no significant difference in Maximum inter-incisal opening $\mathrm{MIO}$ in $\mathrm{mm}$ between preoperative and $7^{\text {th }}$ day postoperatively which has an associated probability value 0.5351 (improved as it reached to its pre-operative normal value).

\section{4- Dexamethasone phonophoresis group/ facial measurements}

As shown in figure (4), paired t-test revealed that there was a significant difference in summation of facial measurement preoperative (normal value) and $2^{\text {nd }}$ day postoperative which has an associated probability value less than 0.0001 . Also, there was a significant difference in summation of facial measurement $2^{\text {nd }}$ day and $7^{\text {th }}$ day postoperative which has an associated probability value less than 0.0001 .

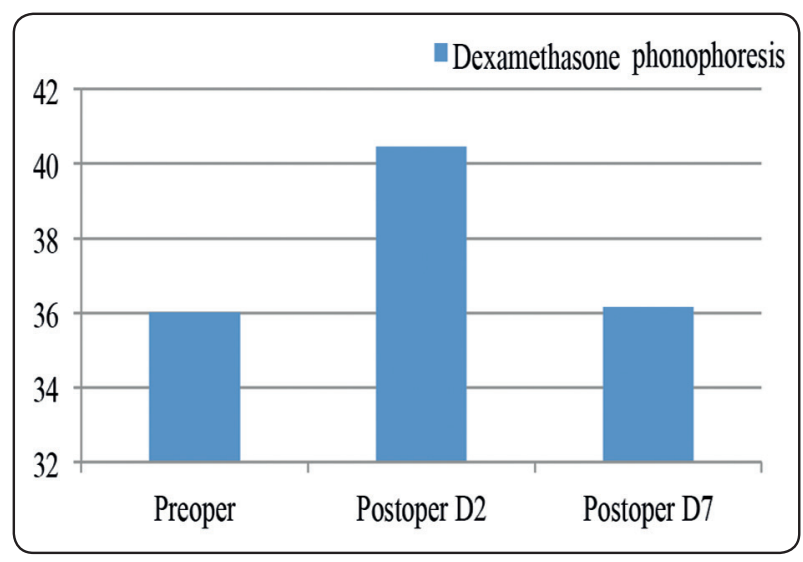

Fig. (4): Mean values of summation of facial measurements of Dexamethasone phonophoresis group. (Preoperativepostoperative day 2- postoperative day 7

TABLE (3) Mean values of Maximum inter-incisal opening MIO of Dexamethasone phonophoresis group preoperative versus postoperative day 2 - postoperative day 2 versus postoperative day 7 and preoperative versus postoperative day 7

\begin{tabular}{|c|c|c|c|c|c|c|}
\hline & Pre & D2 & D2 & D7 & Pre & D7 \\
\hline Mean & $36.01 \mathrm{~mm}$ & $40.46 \mathrm{~mm}$ & $40.46 \mathrm{~mm}$ & $36.15 \mathrm{~mm}$ & $36.01 \mathrm{~mm}$ & $36.15 \mathrm{~mm}$ \\
\hline SD & 1.359 & 1.741 & 1.741 & 1.532 & 1.359 & 1.532 \\
\hline Mean difference & \multicolumn{2}{|c|}{-4.45} & \multicolumn{2}{|c|}{4.31} & \multicolumn{2}{|c|}{-0.14} \\
\hline $\mathrm{T}$ value & \multicolumn{2}{|c|}{37.345} & \multicolumn{2}{|c|}{37.780} & \multicolumn{2}{|c|}{1.740} \\
\hline$P$ value & \multicolumn{2}{|c|}{0.0001} & \multicolumn{2}{|c|}{0.0001} & \multicolumn{2}{|c|}{0.1038} \\
\hline Significance & \multicolumn{2}{|c|}{ Significant } & \multicolumn{2}{|c|}{ Significant } & \multicolumn{2}{|c|}{ Non- Significant } \\
\hline
\end{tabular}


But, there was no significant difference in summation of facial measurement between preoperative (normal value) and $7^{\text {th }}$ day postoperative which has an associated probability value 0.1038 (improved as it reached to its pre-operative normal value).

\section{5- Comparison between groups/ Maximum inter- incisal opening MIO in (mm)}

Maximum inter-incisal opening MIO of both groups: As shown in table (4) and figure (5), unpaired t-test revealed that there was no significant difference in Maximum inter-incisal opening MIO between groups preoperatively, 2nd day, and 7th day postoperative. Regarding preoperative measurements, there was no significant difference as it has an associated probability value 0.7174 . Also, there was no significant difference in Maximum inter-incisal opening MIO 2nd day postoperatively as it has an associated probability value 0.4651 . Moreover, there was no significant difference in Maximum inter-incisal opening MIO 7th day postoperatively as it has an associated probability value 02.226 .

\section{6- Comparison between groups/ facial measurements}

As shown in table (5) and figure (6), unpaired t-test revealed that there was no significant difference in summation of facial measurement between groups preoperatively, $2^{\text {nd }}$ day, and $7^{\text {th }}$ day postoperatively. Regarding preoperative measurements, there was no significant difference as it has an associated probability value 0.7621 . Also, there was no significant difference in summation of facial measurement $2^{\text {nd }}$ day postoperatively as it has an associated probability value 0.358 . Moreover, there was no significant difference in summation of facial measurement $7^{\text {th }}$ day postoperatively as it has an associated probability value 0.7064 .

TABLE (4) Maximum inter-incisal opening MIO in mm of both groups

\begin{tabular}{|c|c|c|c|c|c|}
\hline $\begin{array}{c}\text { Vertical mouth } \\
\text { opening }\end{array}$ & $\begin{array}{c}\text { Mean and SD of US } \\
\text { phonophoresis group }\end{array}$ & $\begin{array}{c}\text { Mean and SD of laser } \\
\text { group }\end{array}$ & T value & P value & Significance \\
\hline Preoperative & $39.7 \pm 02.34$ & $39.4 \pm 02.64$ & 0.3656 & 0.7174 & non-significant \\
\hline $2^{\text {nd }}$ day postoperative & $20.1 \pm 02.67$ & $20.8 \pm 02.24$ & 0.7407 & 0.4651 & non-significant \\
\hline $7^{\text {th }}$ day postoperative & $40 \pm 01.46$ & $39.2 \pm 02.007$ & 1.247 & 0.2226 & non-significant \\
\hline
\end{tabular}

TABLE (5) Unpaired t-test of summation of facial measurements in mm of both groups

\begin{tabular}{|c|c|c|c|c|c|}
\hline $\begin{array}{c}\text { Facial measurement } \\
\text { summation }\end{array}$ & $\begin{array}{c}\text { Mean and SD of US } \\
\text { phonophoresis group }\end{array}$ & $\begin{array}{c}\text { Mean and SD of } \\
\text { laser group }\end{array}$ & T value & P value & Significance \\
\hline Preoperative & $36.01 \pm 1.359$ & $35.87 \pm 1.268$ & 0.3057 & 0.7621 & non-significant \\
\hline $2^{\text {nd }}$ day postoperative & $40.46 \pm 1.741$ & $39.91 \pm 1.493$ & 0.9345 & 0.358 & non-significant \\
\hline $7^{\text {th }}$ day postoperative & $36.15 \pm 1.532$ & $36.35 \pm 1.44$ & 0.3806 & 0.7064 & non-significant \\
\hline
\end{tabular}




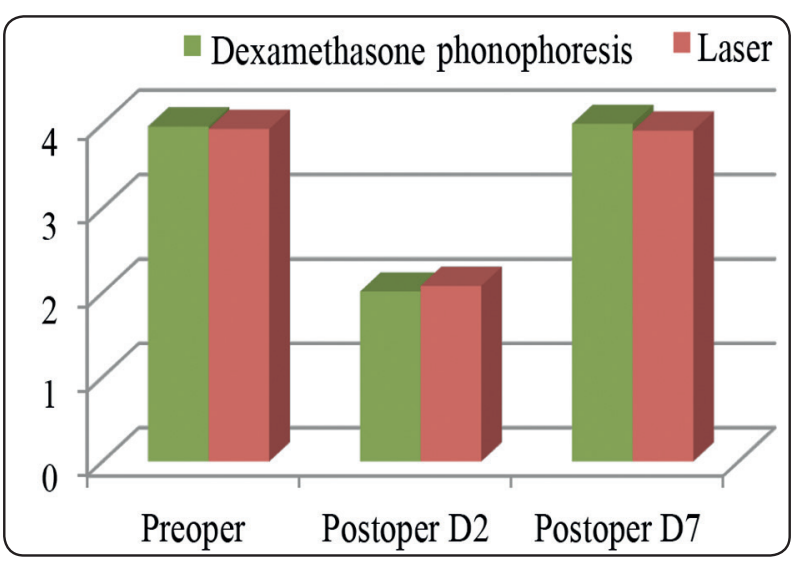

Fig. (5): Mean values of Maximum inter-incisal opening MIO of both group (Preoperative-postoperative day 2postoperative day 7)

\section{DISCUSSION}

Results of the current study revealed that there is no significant difference between administration of dexamethasone phonophoresis and LLLT for the reduction of postoperative edema and trismus. Low level Laser Therapy was significantly effective in decreasing trismus following third molar surgery as manifested by significant increased Maximum interincisal opening MIO, The swelling reduction effect of LLLT may be related to its ability to accelerate the regeneration of lymph vessels and decrease vascular permeability that affect reflectively muscle tissue. Several studies have shown that use of laser application reduced inflammation which aid in the reduction of edema under of the effect; Enhancement of ATP, Stimulation of vasodilatation, Reduction in interkeukin-1, Stabilization of the cellular membrane, Acceleration of leukocytic activity, Increase prostaglandin synthesis, as well Increase angiogenesis ${ }^{(3,6)}$.

Low level Laser Therapy effectiveness results in our study supported by the study carried out by Aras and Gungormus ${ }^{(14)}$, when they evaluated the effect of LLLT on trismus and edema after lower jaw third molar surgery where the masseter muscle was irradiated extra-orally just after surgery. The results demonstrated the efficacy of LLLT on trismus and edema reduction at days 2 and 7 after

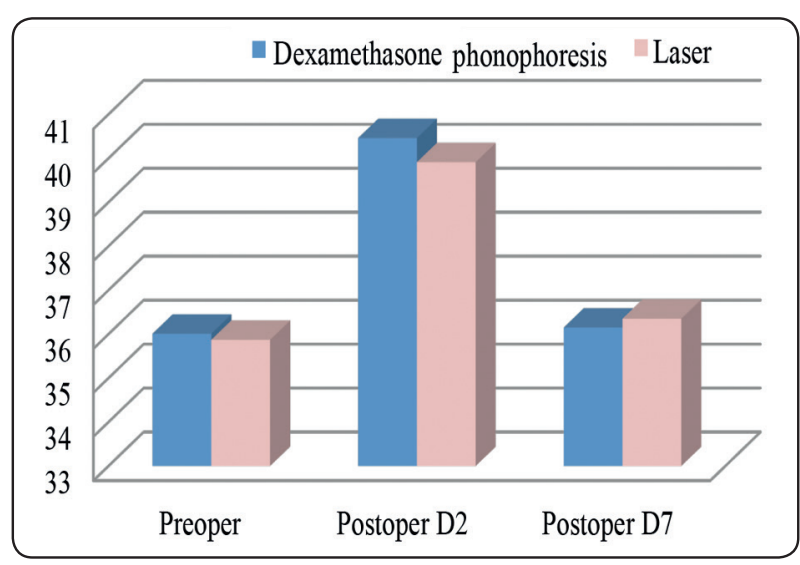

Fig. (6): Mean values of summation of facial measurements of both groups (preoperative-postoperative day 2postoperative day 7

surgery compared to placebo group. Another study was done by the same authors when compared between the effects of extra-oral and intraoral low-level laser therapies (LLLT) on postoperative trismus and oedema following the removal of mandibular third molars using diode laser device with a continuous wavelength of $808 \mathrm{~nm}$ for both of the LLLT groups; The result demonstrated that extra-oral LLLT is more effective than intraoral LLLT for the reduction of postoperative trismus and swelling after extraction of the lower third molar ${ }^{(15)}$.

On the other hand the results of this study about effect of LLLT conflicted by the works reported by Lopez et al where the anti-inflammatory effects of a low-level laser therapy evaluated after the surgical removal of impacted lower third molars using prospective, randomized, and double-blind study was undertaken in 20 healthy patients with two symmetrically impacted lower third molars. The application of a low-level laser with the parameters used in their study did not show beneficial effects in reducing pain, swelling, and trismus after removal of impacted lower third molars ${ }^{(16)}$.While comparing the effects of LLLT and corticosteroids injections on postoperative pain, trismus and edema following surgical removal of mandibular third molar was done in the study of Raouaa et al ${ }^{(17)}$; the results of the study showed that that there is no significant difference between administration of corticosteroids 
and LLLT for the reduction of postoperative pain and trismus but dexamethasone was more effective to reduce swelling on seventh postoperative day.

In spite of the results in our study revealed that both Low level Laser Therapy and Dexamethasone Phonophoresis were significantly effective in decreasing trismus following third molar surgery as manifested by significant increased Maximum inter-incisal opening MIO, but only dexamethasone phonophoresis has a significant effect on reduction of edema as manifested by highly decreased Facial Measurements (FM) while there was no significant difference on edema at $7^{\text {th }}$ day post-operative in laser group. That's demonstrated by several studies confirmed that dexamethasone is an excellent synthetic corticosteroid having very high anti-inflammatory activity, long duration of action, potency and a long biological half-life. It acts by inhibiting phospholipase A2.Corticosteroid also reduced edema by decreasing permeability of capillary endothelium and therefore reduced the amount of fluid, protein, macrophages and other inflammatory cells entering areas of tissue injury $(18,19)$.

In another study aiming to compare the effects of dexamethasone on pain, swelling and trismus administered as one dose preoperatively sub mucosal versus intramuscular injection. The submucosal dexamethasone group showed marked improvement in the mouth opening in the follow ups than the intra-muscular dexamethasone group ${ }^{(20,21)}$. Other studies were concerning reduction of postoperative pain and swelling; indicated that both ultrasound and phonophoresis of dexamethasone are effective methods in pain relief and improving function ${ }^{(22,23)}$

\section{CONCLUSION}

It can be claimed that there is no significant difference between LLLT and dexamethasone phonophoresis for reduction of edema and trismus but only dexamethasone phonophoresis has a significant effect on decreasing edema on seventh post-operative day, while LLLT showed non-significant effect on edema on seventh postoperative day.

\section{REFERENCES}

1. McNeely ML1, Armijo Olivo S, Magee DJ. A systematic review of the effectiveness of physical therapy interventions for temporomandibular disorders. Phys The.; 86:710-2, 2006.

2. Osunde OA, Adebola RA and Omeje UK. Management of inflammatory complications in third molar surgery: A review of literature. A Textbook of Advanced Oral and Maxillofacial Surgery; 11:530-537, 2011.

3. Sierra SO, Deana AM, Ferrari RAM, Albarello PM, Bussadori SK and Fernandes KPS. Effect of low level laser therapy on the post-surgical inflammatory process after third molar removal: study protocol for a double blind randomized controlled trial.Trials; ;4:373 - 2013.

4. Fekrazad R, Chiniforush N, Bouraima SA, Valipour M, Aslani M, Zare Mand Safari OA. Low level laser therapy in management of complications after intraoral surgeries. J Laser Med Sciences; 3:135-140, 2012.

5. Cotler HB, Chow RT, Hambilin MR, Carroll J. The use of Low Level Laser Therapy (LLLT) for Muscloskeletal pain. MOJ Orthop Rheumtol; 2: 2-8, 2015.

6. Pungky Slamet Wisnu Kusuma, Dyah Hariani. Role of laser puncture exposure on gonad maturation mechanism of catfish (Clarias sp.) through $\mathrm{Ca} 2+, \mathrm{PKC}$ and GABA neurotransmitter .Egyptian Journal of Aquatic Research; 43 : 303-305, 2017.

7. Salome WD, Gann NA and Jones DK. Heating effects of ultrasound applied to extracted molars: Is it safe to apply ultrasound to the temporomandibular joint? Physiotherapy; 88: 176-170, 2002.

8. Saliba S, Mistry D J, Perrin DH, Gieck J and Weltman. A Phonophoresis and the absorption of dexamethasone in the presence of an occlusive dressing. J Athl Train.; 42: 349-354, 2007.

9. Ehsan A, Bukhari S, Ashar, Manzoor A and junaid M . Effects of submucosal dexamethasone injection on the post-operative swelling and trismus following surgical extraction of mandibular third molar. J Coll Physicians Surg Pak. ; 24: 489-92, 2014.

10. Haq Z, MCPS and MDS. Use of oral dexamethasone in the impacted mandibular third molar surgery, Pakistan Oral \&Dent.Jr;23 :117-120, 2003.

11. Toopchizadeh V, Javadi R and Sadat BE .Therapeutic efficacy of dexamethasone phonophoresis on symptomatic knee osteoartharities in eldery women. Int J Women's health Reproduction Sci; 2:2330-4456, 2014. 
12. (Ustun Y, Erdogan O, Esen E, Karshi E. Comparison of the effects of 2 doses of methylprednisolone on pain, swelling and trismus after third molar surgery Oral Surg Oral Med Oral Pathol Oral Radiol Endo 2003; 96: 535-539)

13. Seidu A Bello1, Wasiu L Adeyemo2†, Babatunde O Bamgbose $3 \uparrow$, Emeka V Obi1† and Ademola A Adeyinka: Effect of age, impaction types and operative time on inflammatory tissue reactions following lower third molar surgery ; Bello et al. Head \& Face Medicine 2011, 7:8

14. Gungormus M and Aras MH .The effect of low level laser therapy on trismus and facial swelling following surgical extraction of a lower third molar. Photomed Laser Surg; 27(1):21-4, 2009

15. Aras $\mathrm{MH}$, and Gungormus $\mathrm{M}$. Placebo-controlled randomized clinical trial of the effect two different lowlevel laser therapies (LLLT) intraoral and extraoral on trismus and facial swelling following surgical extraction of lower third molar. Laser Med Sci. (5):641-5, 2010.

16. Lopez RM,Vilchez PMA, Gargallo AJ, Arnabat DJ and Gay EC. Efficacy of low level laser therapy in the management of pain, facial swelling and postoperative trismus after a lower third molar extraction. A preliminary study. Lasers Med Sci.) ; 3:559-66, 2012.

17. Raouaa B, Sameh S, Nour BM, Abdellatif C and jamil S Effects of Low Level Laser Therapy versus corticotherapy on pain, trismus and edema after surgical removal of third mandibular molars. A comparative study. Family Med Medical Sci Res; 2:3-10 2013.
18. Markiewicz MR, Brady MF, Ding EL and Dodson TB. Corticosteroids reduce postoperative morbidity after third molar surgery: a systematic review and meta-analysis. $\mathrm{j}$ Oral Maxillofac Surg ; 66 :188-194,2008.

19. Ehsan A, Bukhari S, Ashar, Manzoor A and junaid M. Effects of submucosal dexamethasone injection on the post-operative swelling and trismus following surgical extraction of mandibular third molar. JCPSP; 24: 489-492, 2014.

20. Majid OW and Mahmood WK .Effect of submucosal and intramuscular dexamethasone on post-operative sequelae after third molar surgery comparative study.Br J Oral Maxillofac Surg ;49:647-52, 2011.

21. Saravanan K, Kannan R, John RR and Nantha KCA Single pre-operative dose of sub mucosal dexamethasone is effective in improving post-operative quality of life in the surgical management of impacted third molars:A comparative randomized prospective study. J Maxillofac Oral Surg; 1:67-71, 2016.

22. Saliba S, Mistry D J, Perrin DH, Gieck J and Weltman. A Phonophoresis and the absorption of dexamethasone in the presence of an occlusive dressing. . J Athl Train ; 42:349$354,2007$.

23. Toopchizadeh V, Javadi R and Sadat BE. Therapeutic efficacy of dexamethasone phonophoresis on symptomatic knee osteoartharities in eldery women. International Journal of Women's Health and Reproduction Sciences; 2:2330-4456, 2014 